\title{
Genetic variability of blueberry scorch virus isolates from highbush blueberry in New York State
}

\author{
Elżbieta Kalinowska $^{1} \cdot$ Patricia Marsella-Herrick ${ }^{2} \cdot$ Marc Fuchs $^{2}$
}

Received: 13 December 2014/ Accepted: 15 March 2015/Published online: 27 March 2015

(C) Springer-Verlag Wien 2015

\begin{abstract}
The genetic variability of blueberry scorch virus $(\mathrm{BlScV})$ isolates from New York was determined within a portion of the RNA-dependent RNA polymerase gene and the triple gene block and coat protein $(\mathrm{CP})$ genes. Phylogenetic analysis of 19 New York isolates and other isolates for which sequence information is available in GenBank revealed two distinct clades, regardless of the coding region analyzed, and limited variability within $(0.029 \pm 0.007)$ and between $(0.183 \pm 0.032)$ phylogroups Recombination events were identified in the CP gene of three New York isolates, and codons of the five BlScV genes characterized were found to be under neutral or negative selective pressure.
\end{abstract}

Keywords Blueberry scorch virus · Evolution - Genetic variability $\cdot$ Highbush blueberry $\cdot$ Purifying selection . Recombination

Electronic supplementary material The online version of this article (doi:10.1007/s00705-015-2402-6) contains supplementary material, which is available to authorized users.

Marc Fuchs

mf13@cornell.edu

Elżbieta Kalinowska

ela_kalinowska@op.pl; marc.fuchs@cornell.edu

1 Department of Plath Pathology, Faculty of Horticulture, Biotechnology and Landscape Architecture, Warsaw University of Life Sciences, 159 Nowoursynowska Street, 02-776 Warsaw, Poland

2 Section of Plant Pathology and Plant Microbe Biology, School of Integrative Plant Science, New York State Agriculture Experiment Station, Cornell University, Geneva, NY 14456, USA
Blueberry scorch virus (B1ScV), a member of the genus Carlavirus in the family Betaflexiviridae [2], is one of the most widespread viruses of highbush blueberry ( $\mathrm{Vac}$ cinium corymbosum L.) [30]. The virus has been reported in the United States [4, 5, 7, 8, 23], Canada [28], Italy [16], and Poland [21]. Expression of $\mathrm{BlScV}$ symptoms depends on the cultivar, viral strain, and environmental conditions $[4,28]$. In severe cases of infection during early bloom, blossoms and leaves blight and dry up, resulting in a general decline. Blight symptoms can be restricted to single blossoms and shoots or be more evenly distributed throughout a diseased bush. BIScV infection can be latent for one or two years, or be symptomless in some cultivars [4].

$\mathrm{BlScV}$ is disseminated by vegetative propagation and grafting through the use of infected cuttings. The virus is also transmitted by aphids (Ericaphisfimbriata Richards and Myzuspersicae Sultzer) in a non-persistent mode [4]. The genome of $\mathrm{BlScV}$ consists of a single-stranded RNA molecule of 8,512 nucleotides (nt) in length. The viral RNA is presumed to have a $5^{\prime}$ cap structure and a $3^{\prime}$ polyadenylated tail. The genome has six open reading frames (ORF) that encode (from the $5^{\prime}$ end to the $3^{\prime}$ end) the RNA-dependent RNA polymerase (RdRp), a triple gene block of three overlapping coding regions, e.g., triple gene block 1 (TGB1), triple gene block 2 (TGB2), and triple gene block 3 (TBG3), the coat protein (CP), and ORF6 [2, 5]. Expression of the RdRp is from the genomic RNA, while the other ORFs are presumably expressed from subgenomic RNAs.

So far, genetic variability studies of $\mathrm{BlScV}$ have predominantly focused on partial CP gene fragments of isolates from Canada, Italy, and the United States, with nucleotide sequence identity ranging from 72 to $99 \%$ [15, 27]. No information is available on genetic variability 
outside of the CP gene with the exception of three isolates, one from New Jersey (NJ) and two from British Columbia (BC-1 and BC-2), for which the complete genome sequence is available. The aim of this study was to determine the genetic variability of $\mathrm{BlScV}$ isolates from New York State within the full-length $\mathrm{CP}$ gene, the three full-length TGB genes, and a partial RdRp gene. The genome sequences from New York isolates were compared with those of other isolates and analyzed to determine the strength and direction of selective pressure acting on $\mathrm{BlScV}$ populations.

Blueberry leaves and flowers were collected during the spring-summer of 2014 in plantings located in Steuben (four plantings) and Wayne (one planting) counties in New York State. Plantings in these two counties, which are 160 $\mathrm{km}$ apart, were selected for this study because previous survey efforts documented the presence of $\mathrm{BlScV}$ [7]. Selected plantings were mature (20-25 years old) and primarily consisted of the cultivars 'Bluecrop' and 'Blueray'. Plant material was assayed by DAS-ELISA using commercial antibodies (Agdia, Elkart, IN, USA). BlScV was detected in 59 out of 66 (89\%) highbush blueberry samples from Steuben County, and in 11 out of 31 (35\%) highbush blueberry samples from Wayne County. BlScV-infected bushes from Steuben County exhibited typical symptoms, such as blossom blight and twig dieback, whereas those from Wayne County were symptomless. To confirm the presence of the virus, total RNA was extracted from blueberry leaf and/or blossom samples that reacted positively to $\mathrm{BlScV}$ in ELISA, using an E.Z.N.A. ${ }^{\circledR}$ Plant RNA Kit (Omega Bio-Tek Inc., USA). Specific primers (Table 1) were designed based on the three complete $\mathrm{BIScV}$ genome sequences available in the GenBank database (isolate NJ, accession no. NC_003499; isolate BC-1, accession no. AY941198, and isolate BC-2, accession no. AY941199) and used in immunocapture (IC) reverse transcription (RT)-polymerase chain reaction (PCR) [19] or RT-PCR using a QIAGEN One-Step RT-PCR Kit (Hilden, Germany). The genetic variability of 19 randomly selected $\mathrm{BlScV}$ isolates, 12 from Steuben County and seven from Wayne County, was investigated within five coding regions (Supplementary Table 1).

BLAST analysis of a 434-bp fragment from the $5^{\prime}$ end of the RdRp gene of $19 \mathrm{BlScV}$ isolates from New York revealed sequence identities of $97.9-100 \%$ and $94.4-100$ $\%$ at the nt and amino acid (aa) level, respectively. The sequences of the New York isolates had 86.4-100\% nt sequence identity and $90.3-100 \%$ aa sequence identity to isolates BC-1, BC-2, and NJ. The RdRp fragment analyzed in this study codes for an RNA methyltransferase (MTR) domain, which contains conserved regions in aa position 66-80 (HSHPVCKTLENYILY) and 212-129 (VSSADKIR) [12]. The MTR region of the BIScV population had the lowest variability at the nt and aa level when compared to the other four ORFs characterized in this study (Table 2). Single simple repetitions (SSRs)
Table 1 Primers used for the amplification of the partial RNA-dependent RNA polymerase (RdRp) gene, fulllength triple gene block (TGB) genes, and full-length coat protein $(\mathrm{CP})$ gene of 19 blueberry scorch virus isolates from New York State by IC-RTPCR or RT-PCR

\begin{tabular}{|c|c|c|c|}
\hline Open reading frame & Primer name & Sequence $5^{\prime} \rightarrow 3^{\prime}$ & Position \\
\hline \multirow[t]{2}{*}{$\mathrm{RdRp}$} & RDP_1 ${ }^{\mathrm{ab}}$ & ATGGCACTCACATACAGAAGTCC & $59-81$ \\
\hline & $\mathrm{RDP} \_2^{\mathrm{ab}}$ & TGCCTCTTCAATGCACGATGTTC & $488-510$ \\
\hline \multirow[t]{8}{*}{$\mathrm{CP}$} & njCP1_F $\mathrm{F}^{\mathrm{a}}$ & CTGAGTCCAGAGCATATCGTTGC & $7092-7114$ \\
\hline & njCP1_R $\mathrm{R}^{\mathrm{a}}$ & GTAAACGGAGCTACTGACGCT & $7679-7699$ \\
\hline & njCPnj2_F ${ }^{a}$ & ACCCTTATGGGCGGTTCTCAATTG & $7506-7529$ \\
\hline & njCPnj2_R ${ }^{a}$ & TTTTCATTATACGATATACCCGGCAC & $8349-8374$ \\
\hline & bc2Cp1_F $F^{b}$ & CTGAGTCCAGAGCATATCGTGGCA & $7101-7124$ \\
\hline & bc2CP1_R ${ }^{b}$ & CCGGCTTCCTTTTTCATGATTGC & 7769-7791 \\
\hline & bc2CP2_F $F^{b}$ & ATGAGCTGTACAAGATGGATGTGCA & 7539-7563 \\
\hline & bc2CP2_R ${ }^{b}$ & GGAAACACACGATAACAACGTTC & $8301-8323$ \\
\hline \multirow[t]{4}{*}{ TGB1 } & njTGB1_F ${ }^{a}$ & AATTATGCCATTGAGGTGTCTTTTGCT & $5792-5818$ \\
\hline & njTGB1_R ${ }^{\mathrm{a}}$ & CACTGAAAGCTCAACGCACG & $5597-6616$ \\
\hline & bc2TGB1_F ${ }^{b}$ & TCTTTTGCTTATCTCATGGGGGAGCG & $5817-5842$ \\
\hline & bc2TGB1_R ${ }^{b}$ & TGCCTYGTCAAGCACTGAAAGCT & $6612-6634$ \\
\hline \multirow[t]{4}{*}{ TGB2 and TGB3 } & njTGB2_F ${ }^{a}$ & GGGGTTTTGCTTGCWGCTCATTC & $6486-6508$ \\
\hline & njTGB2_R ${ }^{\mathrm{a}}$ & ATGTATAATCARACGCACACCTGT & $6996-7019$ \\
\hline & bc2TGB2_F ${ }^{b}$ & GGAATTGCGTGGCCAGACTTTTG & $6536-6558$ \\
\hline & bc2TGB2_R $\mathrm{R}^{\mathrm{b}}$ & GCTTCTTTCGGAGGCATAATCGCTT & 7194-7218 \\
\hline
\end{tabular}


Table 2 Predicted evolutionary selection pressure exerted on five proteins encoded by blueberry scorch virus isolates ${ }^{\mathrm{a}}$

\begin{tabular}{llr}
\hline Open reading frame & Amino acid under negative selection ${ }^{\mathrm{b}}$ & $\mathrm{dN}^{\mathrm{d} S^{\mathrm{c}}}$ \\
\hline Partial RdRp & None & 0.042 \\
Full-length CP & None & 0.042 \\
Partial CP & None & 0.042 \\
Full-length TGB1 & $\mathbf{2 6}, 50,55,63,66, \mathbf{7 9}, \mathbf{8 1}, 86,88, \mathbf{9 4}, \mathbf{9 6}, 110,125,146,148,149,152,160$, & 0.087 \\
& $162,165,171, \mathbf{1 8 0}, \mathbf{1 8 1}, \mathbf{1 8 7}, \mathbf{1 9 0}, \mathbf{1 9 2}, 196,202,209,212$ & 0.092 \\
Full-length TGB2 & $\mathbf{2 0}, \mathbf{3 9}, 57,59,60,61,64, \mathbf{7 5}, 95,98$ & 0.119 \\
Full-length TGB3 & $\mathbf{3 1}, \mathbf{3 2}, \mathbf{3 3}, \mathbf{3 5}$ & \\
\hline
\end{tabular}

a The number and ratio of non-synonymous (dN) and synonymous (dS) substitutions were estimated using the Datamonkey server [12] using random effects likelihood (REL), single likelihood ancestor counting (SLAC), and fixed effects likelihood (FEL) models. Only codons with evidence of selection by all three models were taken into account. No amino acid was found under positive selection

b Amino acids located within conserved motifs are in bold

c Ratio of nonsynonymous (dN) to synonymous (dS) substitutions

d All CP gene sequences available in GenBank

have been described in ORF1 of carlaviruses, including $\mathrm{BlScV}$ isolate BC-2, at nt positions 348-353 and 380-385 [1]. The presence of a one-nucleotide (T) SSR repetition was found in 15 (RC-18, RC-28, RC-10, RC-6, RC-5, RC4, H-22-20, H-12-60, H-7-50, H-2-40, F-27-30, F-17-30, RC-22, B-10-60, and A-1-40) out of the $22 \mathrm{BlScV}$ isolates analyzed, including the 19 New York isolates and isolates BC-1, BC-2, and NJ. This repetition was extended to eight nucleotides in the sequence of five $\mathrm{BlScV}$ isolates (A-550, B-1-30, F-12-40, BC-1, and NJ). A second SSR consisting of six $T$ 's was present in the sequence of four isolates (A-5-50, F-12-40, B-1-30, and BC-1). No recombination events were identified in the $5^{\prime}$-terminal ORF1 sequence using the RDP4 Beta 4.39 program [14], and the selective pressure exerted on the corresponding aa was neutral, as shown by estimates of the ratio of nonsynonymous (dN) and synonymous (dS) substitutions using the Datamonkey server [13] (Table 2).

For the full-length TGB1 gene of $19 \mathrm{BlScV}$ isolates from New York, the sequence identity was $82.9-100 \%$ and 90.4-100\% at the nt and aa level, respectively. When this coding region was compared with the corresponding sequence of isolates $\mathrm{BC}-1, \mathrm{BC}-2$, and $\mathrm{NJ}$, identities were 73.7-100 \% at the nt level and 84.6-100\% at the aa level. TGB1 aa alignments revealed five motifs characteristic of viral helicases [11]. Selective pressure analysis revealed negative selection on V/I26 in the first motif ([V/ I]HSVPGAGKSTL[L/I]) in aa position 26-38. The second conserved motif (TLIDEY) at aa position 79-84 was surrounded by two (I and L) instead of four canonical hydrophobic residues [11], and negative selection was found to act on aa I81 and T79. A G/A substitution in the third conserved motif (FAVFADPLQ) was found at aa position 94-102, confirming previous observations for Kalanchoë latent virus (KLV), another carlavirus [18] with three (one $\mathrm{V}$ and two F) instead of four canonical hydrophobic residues preceding the motif [11]. Purifying selection is acting on hydrophobic residues F94 and V96. A T/C substitution was found at aa position 178 of the fourth conserved motif (CIKE[V/L]RGQTF[D/E][S/C]VTFV) at aa position 178-193. This substitution was also reported for several other carlaviruses, as was a $\mathrm{Q} / \mathrm{R}$ substitution at position 183 [10, 15, 18, 20, 24, 30]. Negative selective pressure is acting on K180, E181, F187, V190, and F192 (Table 2). A V/Q substitution at position 208 of the fifth conserved motif (FQC[L/I]TR) at aa position 207-212 has been documented for other carlaviruses $[10,15,18,20,24$, 26, 30]. An A/C substitution at position 209 of the $\mathrm{BlScV}$ motif was observed, but this replacement is usually neutral for protein function [3]. It is noteworthy that purifying selection is exerted on C209 but no SSR tract was identified, contradicting previous observations [1].

For the full-length TGB2 genes of $19 \mathrm{BlScV}$ isolates from New York, the sequence identity was $85-100 \%$ and 88.6-100 \% at the nt and aa level, respectively. Sequence identity of 78.2-100\% at the nt level and of 85.8-100\% at the aa level was found between New York isolates and isolates $\mathrm{BC}-1, \mathrm{BC}-2$ and $\mathrm{NJ}$. The $\mathrm{B} 1 \mathrm{ScV}$ TGB2 protein contains two hydrophobic transmembrane domains at aa positions 9-30 and 75-93 that are separated by a conserved central motif, GDx ${ }_{6} \mathbf{G G x Y x D G ~ [ 1 7 ] , ~ a t ~ a a ~ p o s i t i o n ~ 3 8 - 5 3 . ~}$ Purifying selection is acting on I20 and D39, which are near the N-terminus of TGB2, and on G75, which is localized near the C-terminus of TGB2 (Table 2).

For the full-length TGB3 gene of $19 \mathrm{BlScV}$ isolates from New York, the sequence identity was $90.7-100 \%$ and 95.3-100 \% at the nt and aa level, respectively. This ORF has the second lowest genetic diversity observed within the $\mathrm{BlScV}$ genome (Table 2). When the TGB3 sequence of New York isolates was compared with the corresponding sequences of isolates $\mathrm{BC}-1, \mathrm{BC}-2$ and $\mathrm{NJ}$, identity values ranged between 83 and $100 \%$ at both the nt and aa level. A 
(a)

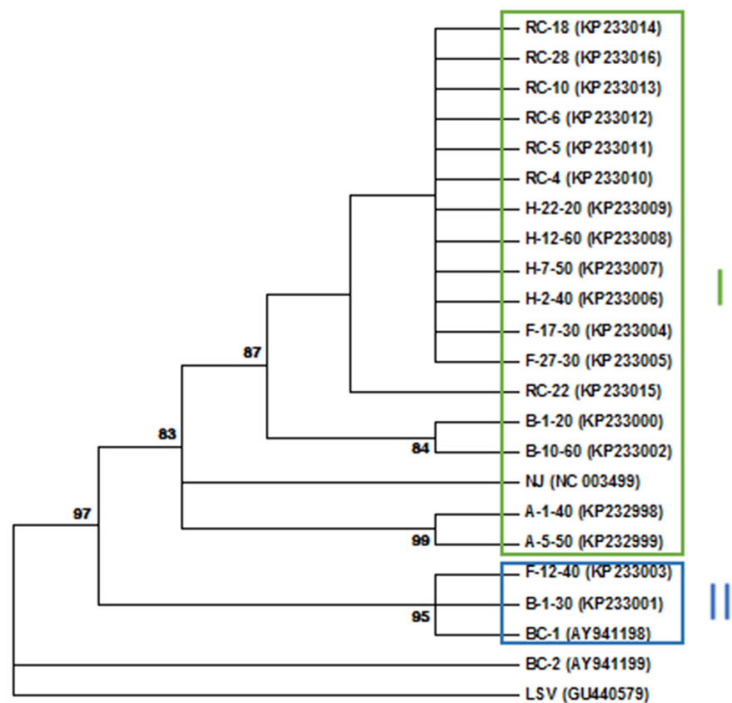

(c)

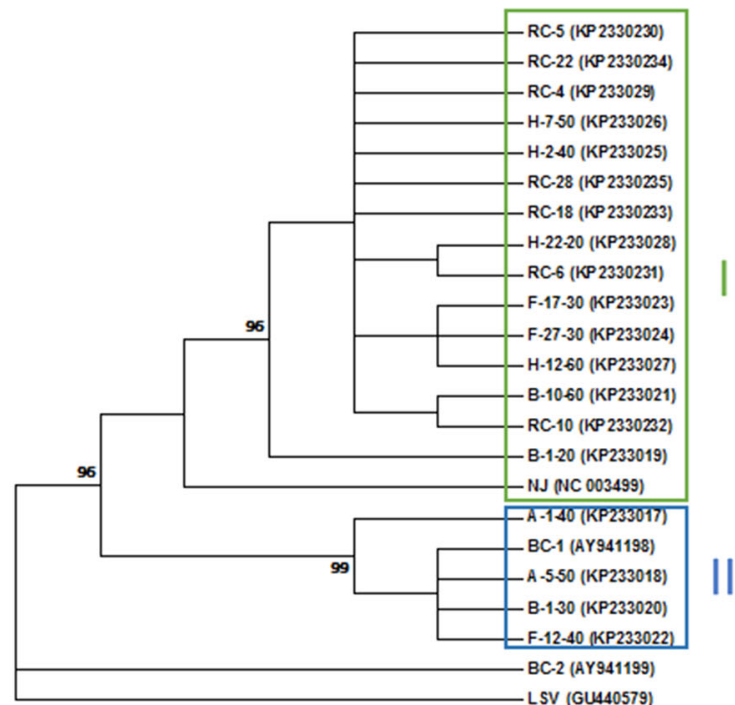

(e)

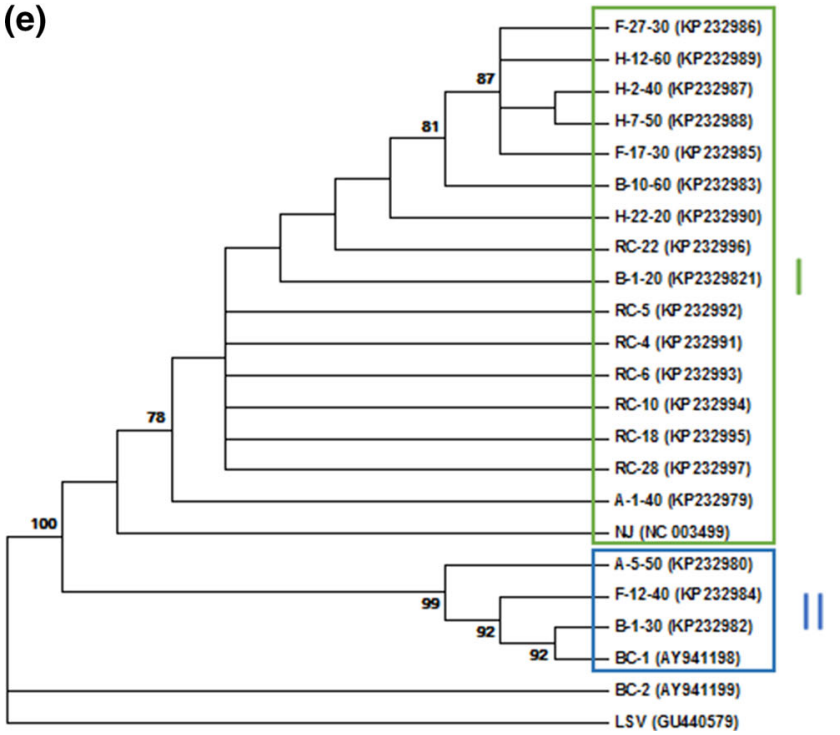

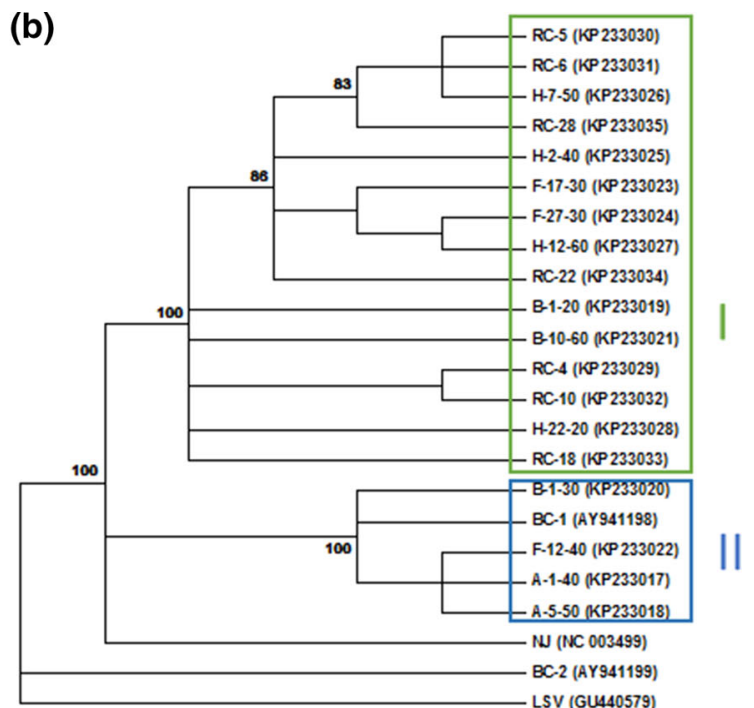

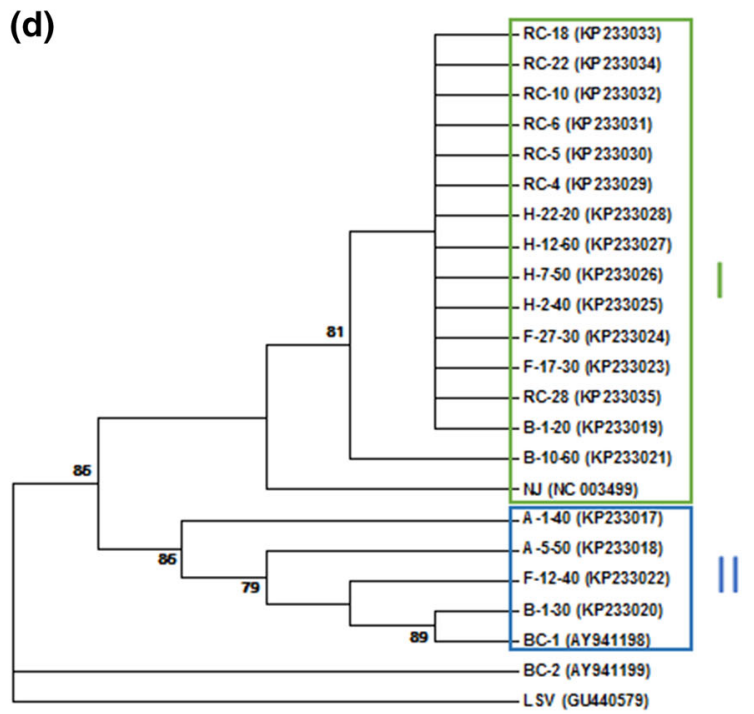


४Fig. 1 Phylogenetic tree of a) a 434-nt-long RNA-dependent RNA polymerase gene fragment, b) the 690-nt full-length triple gene block 1 coding region, c) the 321-nt full-length triple gene block 2 coding region, d) the 195-nt full-length triple gene block 3 coding region, and e) the 939-nt full-length coat protein (CP) gene of 19 blueberry scorch virus isolates from New York State and isolates BC-1, BC-2, and NJ. GenBank accession numbers are in brackets. Bootstrap values are given next to branches. The sequence of lily symptomless virus (LSV) was used as an outgroup

transmembrane domain is present in aa position 4-22, followed by the carlavirus conserved motif $\left(\mathbf{C X}_{5} \mathbf{G} \mathbf{X}_{8} \mathbf{C}\right)$ at aa position 30-44 [17]. Negative selection pressure was found to act on residues V31, I32, V33, and T35 (Table 2).

For the full-length $\mathrm{CP}$ gene of $19 \mathrm{BlScV}$ isolates from New York, the sequence identity was $82.3-100 \%$ and $84-100 \%$ at the nt and aa level, respectively. When this coding region was compared with the full-length $\mathrm{CP}$ gene sequence of isolates $\mathrm{BC}-1, \mathrm{BC}-2$, and $\mathrm{NJ}$, the values were $78.5-100 \%$ at the nt level and 84.6-100\% at the aa level. By analogy to the CPs of viruses containing potex-like TGBs [6], the BIScV CP may be necessary for intercellular transport of the viral genome, and this function could explain the high frequency of synonymous changes in this part of the genome (Table 2). The three-nucleotide (CAC) SSR tract described in isolate BC-2 [1] was not confirmed in this study. Selection pressure analysis of the full-length $\mathrm{CP}$ gene of $22 \mathrm{BlScV}$ isolates revealed neutral selection (Table 2). Analysis of CP gene sequences using the RDP4 Beta 4.39 program [13] indicated a recombination event between nt 454-515 (beginning breakpoint) and 889 (ending breakpoint) with strong statistical support for isolates A-5-50 $\left(p\right.$-value $\left.=1.592 \times 10^{-17}\right)$ and B-1-20 $(p$-value $=$ $\left.3.03 \times 10^{-22}\right)$. For recombinant A-5-50, the putative major parent was isolate F-12-40 and the putative minor parent was isolate F-27-30. For recombinant B-1-20, the putative major and minor parents were isolates F-27-30 and B-1-30, respectively. Another recombination event between nt 40 and 293-371 was confirmed with strong statistical support $\left(p\right.$-value $\left.=1.126 \times 10^{-12}\right)$ for isolate A-1-40. The putative major parent of recombinant A-1-40 was isolate RC-10, and the putative minor parent is unknown. The fact that a recombination event was suspected in only three out of 22 $\mathrm{BlScV}$ isolates analyzed in this study is consistent with the rare occurrence of genetic exchange within the $\mathrm{CP}$ gene of carlaviruses [9, 22, 25, 29].

Phylogenetic relationships within the five ORFs characterized in this study using MEGA6 [27] revealed a grouping of $\mathrm{BlScV}$ isolates into two distinct clades, regardless of the ORF analyzed (Fig. 1). Fifteen BlScV isolates from New York clustered with isolate $\mathrm{NJ}$ in the predominant clade I, and four isolates from New York State, including the three recombinants, clustered with isolate $\mathrm{BC}-1$ in the minor clade II. Isolate BC-2 formed a separate branch by itself in the five phylogenetic trees. Nucleotide sequence divergence within $(0.029 \pm 0.007)$ and between $(0.183 \pm 0.032)$ phylogroups was low. In addition, there was no apparent association between sequence variability and the geographic origin of $\mathrm{BlScV}$ isolates. Similarly, the phylogenetic trees did not group apart New York isolates from symptomatic and asymptomatic highbush blueberry.

In conclusion, while there is an abundance of information on the genetic variability within a portion of the CP gene [15], there is relatively little sequence information from other parts of the genome of $\mathrm{BlScV}$ isolates. Five coding regions of 19 isolates from New York State were characterized by sequencing, showing that purifying selection and recombination are important evolutionary mechanisms in the genetic diversification of BlScV. Although the five $\mathrm{BlScV}$ coding regions are apparently under negative selection, as shown for other carlaviruses [9, 22, 29], codons of the TGB1 and TGB2 genes are under the strongest purifying selection; a moderate purifying selection is exerted on codons of the TGB3 coding region, and neutral selection is exerted on the RdRp and CP genes. TGB translation products are involved in plant cell-to-cell and long-distance movement [2]; therefore genetic conservation allows maintenance of this critical function. Recombination has been described in the $\mathrm{CP}$ genes of other carlaviruses [9, $22,25,29]$, but this is the first report of recombination in $\mathrm{BlScV}$. Together, our findings shed light on the relationship between $\mathrm{BlScV}$ isolates from New York State and other regions, and on the evolution of $\mathrm{BlScV}$ populations.

Acknowledgments We are grateful to the growers who provided access to their blueberry operations and acknowledge the support from USDA-NIFA through the New York State Agriculture Experiment Station and the Polish National Science Center (grant no. 2012/07/N/NZ9/01797). Thanks to Serena Minutillo and David MacUmber for assistance with sample collection. Elżbieta Kalinowska was supported by a fellowship from Warsaw University of Life Sciences for a three-month visit to Cornell University.

\section{References}

1. Alam MC, Singh KA, Sharfuddin C, Ali S (2014) Genome-wide scan for analysis of simple and imperfect microsatellites in diverse carlaviruses. Infect Genet Evol 21:287-294

2. Adams MJ, Candresse T, Hammond J, Kreuze JF, Martelli GP, Namba S, Pearson MN, Ryu KH, Saldarelli P, Yoshikawa N (2012) Family Betaflexiviridae. In: King AMQ, Adams MJ, Carstens EB, Lefkowitz EJ (eds) Virus Taxonomy: ninth report of the international committee of taxonomy of viruses. Elsevier Academic Press, San Diego, p 926

3. Betts MJ, Russell RB (2003) Amino acid properties and consequences of substitutions. In: Barnes MR, Gray IC (eds) Bioinformatics for Geneticists. Wiley, New York, pp 289-314

4. Bristow PR, Martin RR, Windom GE (2000) Transmission, orchard spread, cultivar response, and impact on yield in highbush 
blueberry infected with Blueberry scorch virus. Phytopathology 90:474-479

5. Cavileer TD, Halpern BT, Lawrence DM, Podleckis EV, Martin RR, Hillman BI (1994) Nucleotide-sequence of the carlavirus associated with blueberry scorch and similar diseases. J Gen Virol 75:711-720

6. Chapman S, Hills G, Watts J, Baulcombe D (1992) Mutational analysis of the coat protein gene of potato virus X: effects on virion morphology and viral pathogenicity. Virology 191:223-230

7. Cox K, Cox R, Fuchs M (2012) Emerging blueberry virus concerns for NY: result from blueberry virus survey efforts. N Y Fruit Q 20:9-11

8. DeMarsay A, Hillman BL, Petersen FP, Oudemans PV, Schloemann S (2004) First report of Blueberry scorch virus on highbush blueberry in Connecticut and Massachusetts. Plant Dis 88:572

9. Ge B, He Z, Zhang Z, Wang H, Li S (2014) Genetic variation in potato virus $M$ isolates infecting pepino (Solanum muricatum) in China. Arch Virol 159:3197-3210

10. Hatlestad GJ, Elam L, Gonzalez A, Lloyd AM (2011) Mirabilis jalapa mottle virus: a new carlavirus infecting four o'clocks. Arch Virol 156:2109-2111

11. Kadaré G, Haenni AL (1997) Virus-encoded RNA helicases. J Virol 71:2583-2590

12. Koonin EV, Dolja VV (1993) Evolution and taxonomy of positive-strand RNA viruses: implications of comparative analysis of amino acid sequences. Crit Rev Biochem Mol 28:375-430

13. Kosakovsky Pond SL, Frost SDW (2005) Datamonkey: rapid detection of selective pressures on individual sites of codon alignments. Bioinformatics 21:2531-2533

14. Martin DP, Lemey P, Lott M, Moulton V, Posada D, Lefeuvre P (2010) RDP3: a flexible and fast computer program for analyzing recombination. Bioinformatics 26:2462-2463

15. Matoušek J, Schubert J, Ptácek J, Kozlová P, Dědic P (2005) Complete nucleotide sequence and molecular probing of potato virus S genome. Acta Virol 49:195-205

16. Moretti M, Ciuffo M, Gotta P, Prodorutti D, Bragagna P, Turina M (2011) Molecular characterization of two distinct strains of Blueberry scorch virus $(\mathrm{B} 1 \mathrm{ScV})$ in Northern Italy. Arch Virol 7:1295-1297

17. Morozov SY, Solovyev A (2003) Triple gene block: modular design of a multifunctional machine for plant virus movement. J Gen Virol 84:1351-1366

18. Nicolaisen M, Nielsen SL (2001) Analysis of the triple gene block and coat protein sequences of two strains of Kalanchoë latent carlavirus. Virus Genes 22:265-270
19. Nicolasco G, de Blas C, Torres V, Ponz F (1993) A method combining immunocapture and PCR amplification in microliter plate for the routine diagnosis of plant viruses and subviral pathogens. J Virol Methods 45:201-218

20. Ochoa-Corona FM, Tang J, Lebas BS, Rubio L, Gera A (2010) Diagnosis of broad bean wilt virus 1 and Verbena latent virus in Tropaeolum majus in New Zealand. Australasi Plant Path 39:120-124

21. Paduch-Cichal E, Kalinowska E, Chodorska M, Sala-Rejczak K, Nowak B (2011) Detection and identification of viruses of highbush blueberry and cranberry using serological ELISA test and PCR technique. Acta Sci Pol Hortorum Cultus 10:201-215

22. Pramesh D, Baranwal VK (2013) Molecular characterization of coat protein gene of Garlic common latent virus isolates from India: an evidence for distinct phylogeny and recombination. Virus Genes 47:189-193

23. Schilder A (2010) Shock and scorch survey update. Michi Blueberry Newsl 4:2

24. Scott SW, Zimmerman MT (2008) The complete sequence of ligustrum necrotic ringspot virus, a novel carlavirus. Arch Virol 153:393-396

25. Singh AK, Mahinghara BK, Hallan V, Ram R, Zaidi AA (2008) Recombination and phylogeographical analysis of Lily symptomless virus. Virus Genes 36:421-427

26. Tang J, Harper SJ, Wei T, Clover GR (2010) Characterization of hydrangea chlorotic mottle virus, a new member of the genus Carlavirus. Arch Virol 155:7-12

27. Tamura K, Stecher G, Peterson D, Filipski A, Kumar S (2013) MEGA6: molecular evolutionary genetics analysis version 6.0. Mol Biol Evol 30:2725-2729

28. Wegener LA, Martin RR, Bernardy MG, MacDonald L, Punja ZK (2006) Epidemiology and identification of strains of Blueberry scorch virus on highbush blueberry in British Columbia, Canada. Can J Plant Pathol 28:250-262

29. Zanardo LG, Silva FN, Lima AT, Milanesi DF, Castilho-Urquiza GP, Almeida AM, Zerbini FM, Carvalho CM (2014) Molecular variability of cowpea mild mottle virus infecting soybean in Brazil. Arch Virol 159:727-737

30. Zheng H-Y, Chen J, Zhao M-F, Lin L, Chen J-P, Antoniw JF, Adams MJ (2003) Occurrence and sequences of Lily mottle virus and Lily symptomless virus in plants grown from imported bulbs in Zhejiang province, China. Arch Virol 148:2419-2428 